\title{
Modified Talk Test: A randomised cross-over trial investigating the comparative utility of two "Talk Test" for determining aerobic training zones in overweight and obese patients
}

\section{Ignacio Orizola-Cáceres}

Clinica MEDS

Hugo Cerda-Kohler

Applied Sports Science Unit, High-Performance Center, National Institute Sports, Chile

Carlos Burgos-Jara

Clinica MEDS

Roberto Meneses-Valdes

Clinica MEDS

Rafael Gutierrez-Pino

Clinica MEDS

Carlos Sepulveda ( $\sim$ csepulvedag@ug.uchile.cl)

Clínica MEDS https://orcid.org/0000-0002-7708-9002

Short communication

Keywords: exercise prescription, intensity, aerobic training zones, talk test.

Posted Date: December 15th, 2020

DOI: https://doi.org/10.21203/rs.3.rs-21678/v2

License: (c) (i) This work is licensed under a Creative Commons Attribution 4.0 International License.

Read Full License

Version of Record: A version of this preprint was published at Sports Medicine-Open on April 1st, 2021. See the published version at https://doi.org/10.1186/s40798-021-00315-9. 


\section{Abstract}

Background: to validate the traditional talk test (TTT) and an alternative talk test (ATT; using a visual analog scale) in overweight/obese (OW-OB) patients and to establish its accuracy in determining the aerobic training zones.

Methods: We recruited 19 subjects aged $34.9 \pm 6.7$ years, diagnosed with overweight/obesity (BMI $31.8 \pm$ 5.7). Every subject underwent incremental cycloergometric tests for maximal oxygen consumption, and TTT in a randomized order. At the end of each stage during the TTT each subject read out loud a 40 words text and then had to identify the comfort to talk in two modalities: TTT which consisted in answering "Yes", "I don't know" or "No" to the question Was talking comfortable?, or ATT through a 1 to 10 numeric perception scale (visual scale analog: VAS). The magnitude of differences was interpreted in comparison to the smallest worthwhile change and was used to determine agreement.

Results: Agreement between the power output at the VAS 2-3 of ATT and the power output at the ventilatory threshold 1 (VT1) (very likely equivalent; mean difference -1.3 Watts (W), $90 \%$ confidence limit (CL) $(-8.2 ; 5.6)$, \% chances for higher/similar/lower values of 0.7/99.1/0.2 \%). Also, there was an agreement between the power output at the VAS 6-7 of ATT and the power output at the ventilatory threshold 2 (VT2) (very likely equivalent; mean difference $11.1 \mathrm{~W}, 90 \% \mathrm{CL}(2.8 ; 19.2)$, \% chances for higher/similar/lower values of 0.0/97.6/2.4\%).

Conclusions: ATT is a tool to determine exercise intensity and to establish aerobic training zones for exercise prescription in OW-OB patients.

\section{Keypoints}

- Aerobic training zones delimited by VT1 and VT2 were established through the ATT in overweight and obese people.

- VAS 2-3 and VAS 6-7 identified VT1 and VT2, respectively, in overweight and obese people.

- ATT is a simple tool that could be applied to large populations due to low-cost and easy application and could be used for exercise prescription in community health centers.

\section{Background}

Worldwide, low levels of physical fitness are associated with an increased risk of all-cause and cardiovascular disease [1], and physical inactivity is responsible for a substantial economic burden [2]. Also, poor cardiorespiratory fitness is an independent risk factor for developing non-communicable diseases (NCDs) and cardiovascular disease [3,4]. Noteworthily, regular physical activity reduces the allcause mortality risk by $\sim 14 \%$ and is one of the leading non-pharmacologic strategies for preventing and treating obesity [1]. However, exercise prescription is complicated, depending on duration, frequency, intensity, and exercise type [5]. Moreover, under the same standardized training prescription, there are 
evident individual variations in post-training adaptations [6,7]. Possibly, these individual training responses variations are dose-dependent. Therefore, the control of the physical training load is essential to maximize the benefits associated with health-related exercise [8].

There are several ways of prescribing exercise intensity, and some of these guidelines rely on objective criteria, such as percentages of absolute values of the heart rate reserve (\%HRR) or the maximal oxygen uptake (VO2max). However, there is a convincing body of evidence suggesting that the relative distribution of training intensity is regulated more effectively based on the individual physiological and metabolic response to training $[9,10]$. Exercise intensity determined by the individual physiologic and metabolic response (e.g., ventilatory threshold 1 [VT1], ventilatory threshold 2 [VT2], or lactate threshold) induces homogeneous training response and adaptations to training programs [11]. Besides, is beneficial to identify these thresholds since it allows establishing the three classical training zones: Zone 1 , intensity < VT1; Zone 2, intensities between VT1 and VT2; and Zone 3, intensity > VT2 [12], favoring the control of external and internal training load $[13,14]$. Despite the usefulness of laboratory evaluations individualizing exercise prescriptions, access to these measurements at the healthcare level is limited due to the cost of its implementation [15]. Therefore, research needs to develop low cost and easy to apply training load control methods to improve access to individualized training programs in a specific population. In several countries, community healthcare centers do not have the equipment, infrastructure, and qualified professionals to assess these physiological variables. Moreover, probably the control of exercise intensity during a session only is evaluated with $\mathrm{HR}$, \%HHR, or rating of perceived exertion (RPE). However, if these methods are not associated with physiological and metabolic variables, the effectiveness of physical exercise could be diminished.

Low-cost methods, such as the Talk Test (TT) and the RPE, have been demonstrated to be of value relative to both performance diagnostics and prescription. Within the last years, the TT has been suggested as a useful surrogate of gas exchange thresholds in a variety of populations [16]. The TT is easy to apply and low-cost tool for intensity monitoring [17], and involves an individual reading a similar text during exercise and then being asked if he or she can still speak comfortably [16]. However, the traditional talk test (TTT) only has three options for the question "was talking comfortably?" and lacks quantitative psychometric properties, being questioned as a substitute for objective physiological measures for prescribing individual training exercise [18].

The main objective of the study was to validate the TTT and an alternative TT (ATT; using a visual analog scale) in overweight/obese (OW-OB) patients and to establish its accuracy in determining the aerobic training zones, previously described. We hypothesized that ATT is a valid tool to establish aerobic training zones in OW-OB patients.

\section{Methods}

\section{Participants characteristics}


A total of nineteen subjects with a nutritional diagnosis of $\mathrm{OW}-\mathrm{OB}$ according to $\mathrm{BMI}{ }^{3} 25 \mathrm{~kg} / \mathrm{m}^{2}$, physically inactive according to the World Health Organization (WHO) classification [19], and no diagnosis of NCDs participate in the study. Before the evaluations, the subjects signed an informed consent approved by the Scientific Ethics Committee of the Universidad Finis Terrae (resolution №21/2017). All procedures were performed in compliance at Helsinki Declaration principles for human experiments.

\section{Study design}

The participants visited the laboratory in five separate days nonconsecutive (each evaluation day was intercepted per 3 rest days to prevent unexpected side effects as delayed onset muscle soreness "DOMS"). On the first day, the subjects signed informed consent. Next days, the subjects arrived between 08:00 - 10:00 am and were evaluated in a randomized order for the following procedures: body composition, cardiorespiratory fitness test, TTT, and ATT.

\section{Body composition}

Fat, lean, and fat-free body mass were measured by double energy X-ray absorptiometry (DEXA) using manufacturer-supplied algorithms (Total Body Analysis, version 3.6; Lunar, Madison, WI, United States). The general characterization of subjects is presented in Table 1.

Table 1. Participant's characteristics.

\begin{tabular}{lc}
\hline & $\begin{array}{c}\text { Total } \\
(\mathrm{n}=19)\end{array}$ \\
\hline Age (years) & $34.9 \pm 6.7$ \\
Height $(\mathrm{cm})$ & $170.4 \pm 7.8$ \\
\hline Weight $(\mathrm{kg})$ & $89.5 \pm 15.8$ \\
\hline BMI $\left(\mathrm{kg} \cdot \mathrm{m}^{-2}\right)$ & $30.8 \pm 5.0$ \\
\hline Fat mass $(\%)$ & $37.0 \pm 9.1$ \\
\hline Lean mass $(\%)$ & $59.4 \pm 8.8$ \\
\hline Fat-free mass $(\%)$ & $63.0 \pm 9.0$ \\
\hline
\end{tabular}

Data are shown as mean \pm SD.

Abbreviation: BMI: Body mass index.

\section{Cardiorespiratory fitness}

After a 5-min warm-up at 50 watts and a constant cadence of $55 \pm 5 \mathrm{rpm}$, the participants performed a maximal incremental test on an electronic automatized cycle-ergometer (Cyclus2, Germany). An initial workload of 40 watts (W) was used, with increments of $15 \mathrm{~W}$ (women) and $20 \mathrm{~W}$ (men) every 1 min until exhaustion. The test was performed with a constant cadence of $55 \pm 5$ revolutions per minute (rpm). Gas exchange was recorded continuously with a portable breath-to-breath gas analyzer (Cortex Metalyzer 3B, 
Leipzig, Germany) and was calibrated according to the manufacturer's instructions before each trial. Pulmonary ventilation (VE), oxygen uptake (VO2), expired carbon dioxide (VCO2), and respiratory exchange ratio (RER) were averaged over $10 \mathrm{~s}$ in the mixing chamber mode, with the highest $30 \mathrm{~s}$ value (i.e., three consecutive $10 \mathrm{~s}$ averages) used in the analysis. VO2max was determined according to previously established criteria [20]: (i) plateau in VO2 (i.e., increase $<150 \mathrm{ml} \cdot \mathrm{min}-1$ ), (ii) RER $>1.1$, and (iii) $\geq 90 \%$ of theoretical maximal heart rate. The VO2max was expressed both as absolute values $(L \cdot m i n-1)$ and relative to body mass $(\mathrm{ml} \cdot \mathrm{kg}-1 \cdot \mathrm{min}-1)$. The power output at VO2max (pVO2max) was determined as the minimum workload at which V02max was reached. Ventilatory threshold 1 (VT1) and ventilatory threshold 2 (VT2) were identified separately by three researchers according to the following criteria (24): an increase in VE/VO2 and end-tidal PO2 (PETO2) without a concomitant increase in VE/VCO2 for VT1, and an increase in VE/VO2 and VE/VCO2 and a decrease in end-tidal PCO2 (PETCO2) for VT2. The cardiorespiratory fitness and ventilatory threshold are shown in Table 2.

Table 2. Cardiorespiratory fitness and ventilatory threshold.

\begin{tabular}{llll}
\hline & $\mathrm{VT} 1$ & $\mathrm{VT} 2$ & $\mathrm{VO}_{2} \mathrm{max}$ \\
\hline $\mathrm{VO}_{2} \mathrm{max}\left(\mathrm{ml} \cdot \mathrm{kg}^{-1} \cdot \mathrm{min}^{-1}\right)$ & $14.5 \pm 2.5$ & $22.4 \pm 5.4$ & $28.2 \pm 7.0$ \\
$\mathrm{METs}$ & $4.2 \pm 0.8$ & $6.3 \pm 1.2$ & $8.2 \pm 2.0$ \\
\hline $\mathrm{VO}_{2} \max \left(\mathrm{L} \cdot \mathrm{min}^{-1}\right)$ & $1.3 \pm 0.3$ & $2.0 \pm 0.5$ & $2.6 \pm 0.7$ \\
\hline$\% \mathrm{VO}_{2} \max$ & 51.8 & 77.1 & 96.5 \\
\hline Power (Watts) & $65.3 \pm 20.8$ & $133 \pm 36.0$ & $190.8 \pm 55.3$ \\
\hline $\mathrm{HR}\left(\right.$ beats$\left.\cdot \mathrm{min}^{-1}\right)$ & $109 \pm 12$ & $139 \pm 15.0$ & $163.6 \pm 14.5$ \\
\hline $\mathrm{HR}(\%)$ & 65.7 & 82.0 & 98.7 \\
\hline Ventilation $\left(\mathrm{L} \cdot \mathrm{min}^{-1}\right)$ & $34.2 \pm 8.1$ & $59.5 \pm 16.0$ & $103.8 \pm 28.7$ \\
\hline
\end{tabular}

Data are shown as mean \pm SD.

Abbreviations: $\mathrm{VO}_{2}$ max: maximal oxygen consumption; VT: ventilatory threshold; HR: heart rate; METs: Metabolic equivalent.

\section{Talk test}

After a 10-minute warm-up, subjects performed an incremental test on an electronic automatized cycleergometer (Cyclus2, Germany). The protocol considered load (W) increments every 3 minutes, the time necessary to stabilize ventilation, primary variable for voice production $[21,22]$. During the last 30 seconds of each stage, out loud reading of 40 words from the text "Lectura del Abuelo" was requested. Two methods evaluated the ability to converse during exercise: (i) traditional talk test (TTT) by answering "yes", "no", or "I do not know" to the question "was talking comfortably?", and (ii) alternative talk test (ATT) using a 1 to 10 visual analog scale (VAS) [23]. Both, text "Lectura del Abuelo" and VAS are shown in Figure 1.

\section{Statistical analyses}


Data in the text and figures are presented as mean \pm SD and $90 \%$ confidence limit/interval (CL/Cl). A 90\% confidence interval ( $\mathrm{Cl} ; 1-2 \mathrm{a})$ is used instead of a $95 \% \mathrm{Cl}(1-\mathrm{a})$ because magnitude-based inferences (MBI) performed two one-sided tests (each with an a of $5 \%$ ). All data were first log-transformed to reduce bias arising from non-uniformity error. The magnitude of differences was interpreted in comparison to the smallest worthwhile change (SWC) (Cohen's $d=0.6$ ) [24]. Cohen's $d$ for within-subjects designs is calculated using the average standard deviation of both repeated measures as a standardizer with a Hedges' correction to minimize bias (Cohen's $d_{a d j}$ ) [25]:

\section{Cohen's d adjusted $=\frac{\text { Mdiff }}{(S D 1+S D 2) / 2}$}

This SWC of 0.6 was set as the equivalence region, representing about one stage of difference during the incremental test, and was used to determine agreement. The probability of any substantial difference or realistic equivalence relative to the predefined target values was interpreted using the following scale: $<0.5 \%$, most unlikely; $0.5-5 \%$, very unlikely; $5-25 \%$, unlikely; $25-75 \%$, possibly; $75-95 \%$, likely; $95-99.5 \%$, very likely; $>99.5 \%$, most likely [26]. Effects were declared relevant if the outcome probability was likely $(\geq 75 \%)$ (i.e., methods were considered in agreement and, therefore, interchangeable). Statistical analysis was performed with the "mbir" package of the R software [27]. Statistical significance was set at $p<0.05$.

\section{Results}

We recruited 34 volunteer participants, of which six were excluded because they did not meet the criteria for entering the study, and ten did not complete all testing procedures. The final analysis, therefore, included 19 patients who completed the evaluations.

\section{Agreement between Traditional Talk Test and ventilatory thresholds}

Results of the equivalence tests between TTT and ventilatory thresholds are presented in Figure 2 and Table 3. Evidence for an agreement was observed between the power output at the "first no" (FN) and the power output at the ventilatory threshold 2 (most likely equivalent; mean difference $-2.9 \mathrm{~W}, 90 \% \mathrm{CL}(-10.9$; 5.1)). There was no agreement between the power output at the "last yes" (LY) and the power output at the ventilatory threshold 1 (unlikely equivalent; mean difference $-22.4 \mathrm{~W}, 90 \% \mathrm{CL}(-31.3 ;-13.3)$ ). As represented in Figure 2A, there was an agreement between the power output at the LY and the power output at the VAS $4-5$ of ATT (very likely equivalent; mean difference $7.1 \mathrm{~W}, 90 \% \mathrm{CL}(0.4 ; 13.7)$ ).

Table 3. Analysis of agreement. 


\begin{tabular}{|c|c|c|c|c|c|c|}
\hline Variable & $\begin{array}{c}\text { Mean of } \\
\text { differences }\end{array}$ & CI $90 \%$ & $\begin{array}{l}\text { Chances of true } \\
\text { differences (\%) }\end{array}$ & $\begin{array}{c}\text { Effect Size Cohen's } \\
d_{\text {adj }}(\text { CI 90\%) }\end{array}$ & $\begin{array}{l}\text { Magnitude of } \\
\text { effect }\end{array}$ & $\begin{array}{c}\mathrm{p}- \\
\text { value }\end{array}$ \\
\hline \multicolumn{7}{|c|}{ Traditional Talk Test: Last stage where answer was "yes" } \\
\hline $\begin{array}{l}\text { WTTT/LY vs } \\
\text { WVT1 }\end{array}$ & -22.4 & $\begin{array}{l}-31.3 / \\
-13.3\end{array}$ & $\begin{array}{c}\text { Unlikely Equivalent } \\
(87.3 / 12.7 / 0.0)\end{array}$ & $-0.85(-1.22 /-0.48)$ & Moderate & 0.001 \\
\hline $\begin{array}{l}\text { WTTT/LY vs } \\
\text { WATT/2-3 }\end{array}$ & -21.1 & $\begin{array}{l}-27.5 / \\
-14.5\end{array}$ & $\begin{array}{c}\text { Unlikely Equivalent } \\
(90.3 / 9.7 / 0.0)\end{array}$ & $-0.78(-1.01 /-0.55)$ & Moderate & 0.000 \\
\hline $\begin{array}{l}\text { WTTT/LY vs } \\
\text { WATT/4-5 }\end{array}$ & 7.1 & $\begin{array}{l}0.4 / \\
13.7\end{array}$ & $\begin{array}{c}\text { Very Likely } \\
\text { Equivalent } \\
(0.0 / 97.1 / 2.9)\end{array}$ & $0.31(0.07 / 0.56)$ & Trivial & 0.039 \\
\hline \multicolumn{7}{|c|}{ Traditional Talk Test: First stage where answer was "no" } \\
\hline $\begin{array}{c}\text { WTTT/FN vs } \\
\text { WVT2 }\end{array}$ & -2.9 & $\begin{array}{c}-10.9 / \\
5.1\end{array}$ & $\begin{array}{c}\text { Most Likely } \\
\text { Equivalent } \\
(0.1 / 99.9 / 0.0)\end{array}$ & $-0.10(-0.34 / 0.13)$ & Trivial & 0.455 \\
\hline $\begin{array}{l}\text { WTTT/FN vs } \\
\text { WATT/4-5 }\end{array}$ & -41.6 & $\begin{array}{l}-49.7 / \\
-33.3\end{array}$ & $\begin{array}{l}\text { Most Unlikely } \\
\text { Equivalent } \\
(100.0 / 0.0 / 0.0)\end{array}$ & $-1.36(-1.60 /-1.12)$ & Large & 0.000 \\
\hline $\begin{array}{l}\text { WTTT/FN vs } \\
\text { WATT/6-7 }\end{array}$ & -13.9 & $\begin{array}{c}-18.7 / \\
-9.1\end{array}$ & $\begin{array}{c}\text { Very Likely } \\
\text { Equivalent } \\
(1.9 / 98.1 / 0.0) \\
\end{array}$ & $-0.41(-0.56 /-0.25)$ & Trivial & 0.000 \\
\hline \multicolumn{7}{|c|}{ Alternative Talk Test: Visual Analogue Scale } \\
\hline $\begin{array}{l}\text { WATT/2-3 vs } \\
\text { WVT1 }\end{array}$ & -1.3 & $\begin{array}{l}-8.2 / \\
5.6\end{array}$ & $\begin{array}{c}\text { Very Likely } \\
\text { Equivalent } \\
(0.7 / 99.1 / 0.2)\end{array}$ & $-0.06(-0.40 / 0.28)$ & Trivial & 0.763 \\
\hline $\begin{array}{l}\text { WATT/4-5 vs } \\
\text { WVT1 }\end{array}$ & -29.5 & $\begin{array}{l}-37.6 / \\
-21.2\end{array}$ & $\begin{array}{l}\text { Most Unlikely } \\
\text { Equivalent } \\
(99.8 / 0.2 / 0.0)\end{array}$ & $-1.34(-1.73 /-0.95)$ & Large & 0.000 \\
\hline $\begin{array}{l}\text { WATT/4-5 vs } \\
\text { WVT2 }\end{array}$ & 38.7 & $\begin{array}{l}27.1 / \\
50.2\end{array}$ & $\begin{array}{l}\text { Most Unlikely } \\
\text { Equivalent } \\
(0.0 / 0.4 / 99.6)\end{array}$ & $1.18(0.84 / 1.52)$ & Moderate & 0.000 \\
\hline $\begin{array}{l}\text { WATT/6-7 vs } \\
\text { WVT2 }\end{array}$ & 11.1 & $\begin{array}{l}2.8 / \\
19.2\end{array}$ & $\begin{array}{c}\text { Very Likely } \\
\text { Equivalent } \\
(0.0 / 97.6 / 2.4)\end{array}$ & $0.29(0.04 / 0.54)$ & Trivial & 0.058 \\
\hline
\end{tabular}

Abbreviations: SWC: Smallest worthwhile change; WTTT/LY: Watts of traditional talk test in the last stage where the answer was "yes"; WVT1: Watts at ventilatory threshold 1; WATT: Watts of alternative talk test; WTTT/FN: Watts of traditional talk test in the first stage where the answer was "no"; WVT2: Watts at ventilatory threshold 2; W: Watts.

\section{Agreement between Alternative Talk Test and ventilatory thresholds}

Figures 2B shows an agreement between the power output at the VAS 2-3 of ATT and the power output at the ventilatory threshold 1 (very likely equivalent; mean difference $-1.3 \mathrm{~W}, 90 \% \mathrm{CL}(-8.2 ; 5.6)$ ). There was no agreement between the power output at the VAS 4-5 of ATT and the power output at the ventilatory threshold 1 (most unlikely equivalent; mean difference -29.5 W, $90 \% \mathrm{CL}(-37.6 ;-21.2)$ ). Results showed no agreement between the power output at the VAS $4-5$ of ATT and the power output at the ventilatory threshold 2 (most unlikely equivalent; mean difference $38.7 \mathrm{~W}, 90 \% \mathrm{CL}(27.1 ; 50.2)$ ). As represented in Figure 2B, there was an agreement between the power output at the VAS 6-7 of ATT and the power output at the ventilatory threshold 2 (very likely equivalent; mean difference $11.1 \mathrm{~W}, 90 \% \mathrm{CL}(2.8 ; 19.2)$ ). There was an agreement between the power output at the VAS 6-7 of ATT and the power output at the "first no" of TTT (very likely equivalent; mean difference -13.9 W, $90 \%$ CL $(-18.7 ;-9.1)$ ). 


\section{Discussion}

The regulation and control of exercise intensity are some of the most challenging parts of exercise prescription. There are several ways of prescribing exercise intensity, and some of these recommendations are based on objective criteria, such as percentages of absolute values of the \%HRR or V02max. However, recent investigations propose a more individualized exercise prescription to personalize a training regime based on individual metabolic responses and, therefore, enhance the potential benefits of regular physical activity [11]. Therefore, the goal of this investigation was to prove the usefulness of the TTT and/or ATT as a low-cost tool to determine exercise intensity and establish aerobic training zones for exercise prescription in OW-OB patients.

Our main finding shows that the three aerobic training zones delimited by VT1 and VT2 could be established through the TT, primarily through the ATT. Regarding the TTT, previous studies have shown an association between VT1 and the last stage of the TT where talking was comfortable in healthy subjects $[28,29,16]$ and between VT2 with TT stages where comfort to talk is lost in patients with heart diseases [30,31]. However, these previous studies used the VO2 values to compare intensities between the TTT and ventilatory thresholds. This methodology does not allow obtaining external load values (e.g., watts) that can be used for prescribing and controlling aerobic training.

In our study, the TTT failed to determine the transition from zone 1 to zone 2 because we found no agreement between the power output of the different answers related to the TTT and the power output at VT1. The transition threshold between zone 2 and zone 3 could be established with the power output at the first stage where the answer was "no," which was most likely equivalent to the power output at VT2. This lack of consistency with previous results could be related to the statistical analysis. The previous studies used correlation analysis (e.g., Pearson correlation) [16,28], which focuses on the association of changes in two outcomes that often measure quite different constructs [32]. Our study used agreement analysis, which measures the degree of concordance in the results between two or more assessments of the variable of interest and assumes that the variables measure the same construct [32], being agreement analysis better to assess if methods are interchangeable [33]. To our knowledge, there is only one study in well-trained cyclists that measure agreement between workload at VTs and TT. Rodriguez et al. found agreement between the power output at the first stage where the answer was "I do not know" and the power output associated with VT1 [34]. Also, they found an agreement between the power output at the first stage where the answer was "no" and the power output associated with VT2, results that partially disagree with our recent findings in OW-OB patients.

Regarding the ATT, the absence of psychometric properties of the TTT may induce an under or overestimation of the degree of talking comfort during physical exercise in physically inactive persons. The ATT would allow identifying the "difficult to talk" with numeric magnitudes by giving a quantitative variable to the TT $[35,36,18]$. Speech production during exercise is associated with changes in physiological variables related to exercise, being the consequence of the need to adapt the breathing pattern compatible with speech production. Accordingly, Rotstein et al. found a significant association 
between $\mathrm{VO} 2, \mathrm{HR}$, and $\mathrm{VE}$ responses and the ratings of perceived speech production difficulty. Our results agree with these previous findings, showing that the intensity (power output) associated with VT1 is very likely equivalent to the last stage where talking was "very easy" (VAS 2-3), allowing to determine the threshold to zone 1. The power output at the first stage where talking was "hard" (VAS 6-7) was very likely equivalent to the power output at VT2 (Table 3), which allows determining the threshold to zone 3 . The power output where talking was "somewhat hard" (VAS 4-5) was most likely higher than the power output at VT1 and most likely lower than the power output at VT2, thus, representing the intensity related to zone 2 (Figure 2B). Taken together, these results showed that the ATT could be used to determine exercise intensity and establish aerobic training zones for exercise prescription in OW-OB patients. The main limitation of clinical context is to have a low-cost tool to prescribe physical exercise. To solve this problem, ATT is a simple tool that could be applied to large populations due to its low-cost and easy application. However, further research is needed to determine the effect of endurance training controlled with ATT on obese people.

Some limitations exist in this study as the low number of subjects recruited. Several studies have similar limitations[16,34,37]. Possibly the specific characteristics of them (e.g., participants with OW/OB) reduced the adherence of the participants. Another important issue to resolve for future studies is replicating the study on a treadmill with TTT and ATT in OW/OB patients with and without comorbidities. Interestingly, these tools could help healthcare professionals promote the massive practice of physical exercise in a population with the absence of technology to control the training program load. Finally, lowcost tools would help to improve the capacity of health care professionals to control exercise intensity, improving the health benefits of exercise and physical activity.

\section{Conclusions}

ATT is a low-cost and easy to apply tool to determine exercise intensity and to establish aerobic training zones for exercise prescription in OW-OB patients. The TTT could under or overestimate the physical effort in patients diagnosed with $\mathrm{OW}-\mathrm{OB}$, specifically at the training zone 1.

\section{Abbreviations}

BMI: Body mass index; $\mathrm{VO}_{2}$ max: maximal oxygen consumption; $\mathrm{VT}$ : ventilatory threshold; HR: heart rate; METs: Metabolic equivalent; SWC: Smallest worthwhile change; WTTT/LY: Watts of traditional talk test in the last stage where the answer was "yes"; WVT1: Watts at ventilatory threshold 1; WATT: Watts of alternative talk test; WTTT/FN: Watts of traditional talk test in the first stage where the answer was "no"; WVT2: Watts at ventilatory threshold 2; W: Watts.

\section{Declarations}

\section{Ethical Approval and Consent to participate}


The Scientific Council of University Finis Terrae approved the research (N²1/2017). 58076/14-11-2018). All the participants gave written consent.

\section{Consent for publication}

All the gave written consent for publication of data.

\section{Availability of data and materials}

Please contact author for data requests.

\section{Competing interests}

The authors, Ignacio Orizola-Cáceres, Hugo Cerda-Kohler, Carlos Burgos-Jara, Roberto Meneses-Valdes, Rafael Gutierrez-Pino and Carlos Sepúlveda, declare that they have no competing interests.

\section{Funding}

This research received no external funding.

\section{Authors' contributions}

IOC has carried out the conceptualization, methodology, recruitment of participants, data collection, as well as the statistical study, writing - original draft. HCK has been the reviewer of the work helping in the statistical analysis and perfection of the methodological aspects. CBJ, RMV and RGP has carried out data collection and data curation. CS has collaborated in the project administration, methodology, writing and guiding for its edition, and in the perfection of the methodological aspects. All authors have contributed to proof-reading of the manuscript and have approved the final article.

\section{Acknowledgements}

Not applicable.

\section{Author details}

${ }^{1}$ Unidad de Fisiología Integrativa, Laboratorio de Ciencias del Ejercicio, Clínica MEDS, Santiago, Chile.

${ }^{2}$ Applied Sports Science Unit, High-Performance Center, National Institute of Sports, Chile.

\section{References}

1. Blair SN, Kohl HW, Barlow CE, Paffenbarger RS, Gibbons LW, Macera CA. Changes in physical fitness and all-cause mortality. A prospective study of healthy and unhealthy men. JAMA. 1995;273:1093-8.

2. Lear SA, Hu W, Rangarajan S, Gasevic D, Leong D, Iqbal R, et al. The effect of physical activity on mortality and cardiovascular disease in 130000 people from 17 high-income, middle-income, and 
low-income countries: the PURE study. Lancet. 2017;390:2643-54.

3. Ross R, Blair SN, Arena R, Church TS, Després J-P, Franklin BA, et al. Importance of Assessing Cardiorespiratory Fitness in Clinical Practice: A Case for Fitness as a Clinical Vital Sign: A Scientific Statement From the American Heart Association. Circulation. 2016;134:e653-99.

4. Nyberg ST, Batty GD, Pentti J, Virtanen M, Alfredsson L, Fransson El, et al. Obesity and loss of disease-free years owing to major non-communicable diseases: a multicohort study. Lancet Public Health. 2018;3:e490-7.

5. Burgos C, Henríquez-Olguín C, Ramírez-Campillo R, Mahecha Matsudo S, Cerda-Kohler H, Burgos C, et al. Exercise as a tool to reduce body weight. Revista médica de Chile. 2017;145:765-74.

6. Bouchard C, Leon AS, Rao DC, Skinner JS, Wilmore JH, Gagnon J. The HERITAGE family study. Aims, design, and measurement protocol. Med Sci Sports Exerc. 1995;27:721-9.

7. Timmons JA, Knudsen S, Rankinen T, Koch LG, Sarzynski M, Jensen T, et al. Using molecular classification to predict gains in maximal aerobic capacity following endurance exercise training in humans. J Appl Physiol. 2010;108:1487-96.

8. Montero D, Lundby C. Refuting the myth of non-response to exercise training: "non-responders" do respond to higher dose of training. J Physiol (Lond). 2017;595:3377-87.

9. Scharhag-Rosenberger F, Meyer T, Gässler N, Faude O, Kindermann W. Exercise at given percentages of V02max: heterogeneous metabolic responses between individuals. J Sci Med Sport. 2010;13:749.

10. Condello G, Reynolds E, Foster C, de Koning JJ, Casolino E, Knutson M, et al. A simplified approach for estimating the ventilatory and respiratory compensation thresholds. J Sports Sci Med. 2014;13:309-14.

11. Weatherwax RM, Ramos JS, Harris NK, Kilding AE, Dalleck LC. Changes in Metabolic Syndrome Severity Following Individualized Versus Standardized Exercise Prescription: A Feasibility Study. Int J Environ Res Public Health. 2018;15.

12. Skinner JS, McLellan TM, McLellan TH. The transition from aerobic to anaerobic metabolism. Res Q Exerc Sport. 1980;51:234-48.

13. Pallarés JG, Morán-Navarro R, Ortega JF, Fernández-Elías VE, Mora-Rodriguez R. Validity and Reliability of Ventilatory and Blood Lactate Thresholds in Well-Trained Cyclists. PLoS ONE. 2016;11:e0163389.

14. Zapata-Lamana R, Henríquez-Olguín C, Burgos C, Meneses-Valdés R, Cigarroa I, Soto C, et al. Effects of Polarized Training on Cardiometabolic Risk Factors in Young Overweight and Obese Women: A Randomized-Controlled Trial. Front Physiol. 2018;9:1287.

15. Jamnick NA, Botella J, Pyne DB, Bishop DJ. Manipulating graded exercise test variables affects the validity of the lactate threshold and [Formula: see text]. PLoS ONE. 2018;13:e0199794.

16. Quinn TJ, Coons BA. The Talk Test and its relationship with the ventilatory and lactate thresholds. J Sports Sci. 2011;29:1175-82. 
17. Jeanes EM, Jeans EA, Foster C, Porcari JP, Gibson M, Doberstein S. Translation of exercise testing to exercise prescription using the talk test. J Strength Cond Res. 2011;25:590-6.

18. Rotstein A, Meckel Y, Inbar O. Perceived speech difficulty during exercise and its relation to exercise intensity and physiological responses. Eur J Appl Physiol. 2004;92:431-6.

19. Nuttall FQ. Body Mass Index. Nutr Today. 2015;50:117-28.

20. Howley ET, Bassett DR, Welch HG. Criteria for maximal oxygen uptake: review and commentary. Med Sci Sports Exerc. 1995;27:1292-301.

21. Meckel $Y$, Rotstein A, Inbar 0 . The effects of speech production on physiologic responses during submaximal exercise. Med Sci Sports Exerc. 2002;34:1337-43.

22. Foster C, Porcari JP, Ault S, Doro K, Dubiel J, Engen M, et al. Exercise prescription when there in no exercise test: the talk test. Kinesiology. 2018;50:33-48.

23. De Lucca L, Freccia GW, Silva AEL e, Oliveira FR de. Talk test as method to control exercise intensity. Revista Brasileira de Cineantropometria \&amp; Desempenho Humano. 2012;14:114-24.

24. Batterham AM, Hopkins WG. Making meaningful inferences about magnitudes. Int J Sports Physiol Perform. 2006;1:50-7.

25. Lakens D. Calculating and reporting effect sizes to facilitate cumulative science: a practical primer for t-tests and ANOVAs. Front Psychol [Internet]. 2013 [cited 2019 Feb 9];4. Available from: https://www.ncbi.nlm.nih.gov/pmc/articles/PMC3840331/

26. Macpherson TW, McLaren SJ, Gregson W, Lolli L, Drust B, Weston M. Using differential ratings of perceived exertion to assess agreement between coach and player perceptions of soccer training intensity: An exploratory investigation. Journal of Sports Sciences. Routledge; 2019;37:2783-8.

27. Peterson K, Caldwell A. mbir: Magnitude-Based Inferences. Journal of Open Source Software. 2019;4:746.

28. Recalde JP, T P, Foster, Carl, Skemp-Arlt, M K, et al. The Talk Test as a simple marker of ventilatory threshold. South African Journal of Sports Medicine. South African Sports Medicine Association; 2002;2002:5-8.

29. Persinger R, Foster C, Gibson M, Fater DCW, Porcari JP. Consistency of the talk test for exercise prescription. Med Sci Sports Exerc. 2004;36:1632-6.

30. Zanettini R, Centeleghe P, Franzelli C, Mori I, Benna S, Penati C, et al. Validity of the Talk Test for exercise prescription after myocardial revascularization. Eur J Prev Cardiol. 2013;20:376-82.

31. Reed JL, Pipe AL. The talk test: a useful tool for prescribing and monitoring exercise intensity. Curr Opin Cardiol. 2014;29:475-80.

32. Liu J, Tang W, Chen G, Lu Y, Feng C, Tu XM. Correlation and agreement: overview and clarification of competing concepts and measures. Shanghai Arch Psychiatry. 28:115-20.

33. Watson PF, Petrie A. Method agreement analysis: a review of correct methodology. Theriogenology. 2010;73:1167-79. 
34. Rodríguez-Marroyo JA, Villa JG, García-López J, Foster C. Relationship between the talk test and ventilatory thresholds in well-trained cyclists. J Strength Cond Res. 2013;27:1942-9.

35. Borg GA. Perceived exertion: a note on "history" and methods. Med Sci Sports. 1973;5:90-3.

36. Borg GA. Psychophysical bases of perceived exertion. Med Sci Sports Exerc. 1982;14:377-81.

37. Gillespie BD, McCormick JJ, Mermier CM, Gibson AL. Talk test as a practical method to estimate exercise intensity in highly trained competitive male cyclists. J Strength Cond Res. 2015;29:894-8.

\section{Figures}

Text "Lectura del Abuelo"

\section{El Abuelo}

"Usted quiere saber sobre mi abuelo. Bueno, él tiene cerca de noventa y tres años de edad y aún piensa tan lúcidamente como siempre. Se visto solo, y se pone su vieja chaqueta negra que comúnmente, tiene varios botones menos"
Visual scale analog ¿Fue fácil o difícil hablar? 1

$2-3$

$4-5$

$6-7$

$8-9$

10
Extremadamente fácil Muy fácil Levemente difícil Dificil Muy difíil Extremadamente difícil

\begin{tabular}{c|cl}
\hline Grandfather & \multicolumn{2}{|c}{ Was easy or hard to talk? } \\
\hline & 1 & Extremely easy \\
"You want to know about my grandfather. Well, he is about & $2-3$ & Very easy \\
ninety-three years old and still thinks as lucidly as ever. He looks & $4-5$ & Slightly difficult \\
alone, and puts on his old black jacket that commonly has & $6-7$ & Hard \\
several less buttons" & $8-9$ & Very hard \\
& 10 & Extremely hard \\
\hline
\end{tabular}

\section{Figure 1}

Text "Lectura del Abuelo" and visual scale analog. 
"Usted quiere saber sobre mi abuelo. Bueno, él tiene cerca de

1

$2-3$

$4-5$

$6-7$

$8-9$

10
Extremadamente fácil

Muy fácil

Levemente difícil

Dificil

Muy difícil

Extremadamente difícil

\begin{tabular}{c|cl}
\hline Grandfather & \multicolumn{2}{|c}{ Was easy or hard to talk? } \\
\hline & 1 & Extremely easy \\
"You want to know about my grandfather. Well, he is about & $2-3$ & Very easy \\
ninety-three years old and still thinks as lucidly as ever. He looks & $4-5$ & Slightly difficult \\
alone, and puts on his old black jacket that commonly has & $6-7$ & Hard \\
several less buttons" & $8-9$ & Very hard \\
& 10 & Extremely hard \\
\hline
\end{tabular}

\section{Figure 1}

Text "Lectura del Abuelo" and visual scale analog.
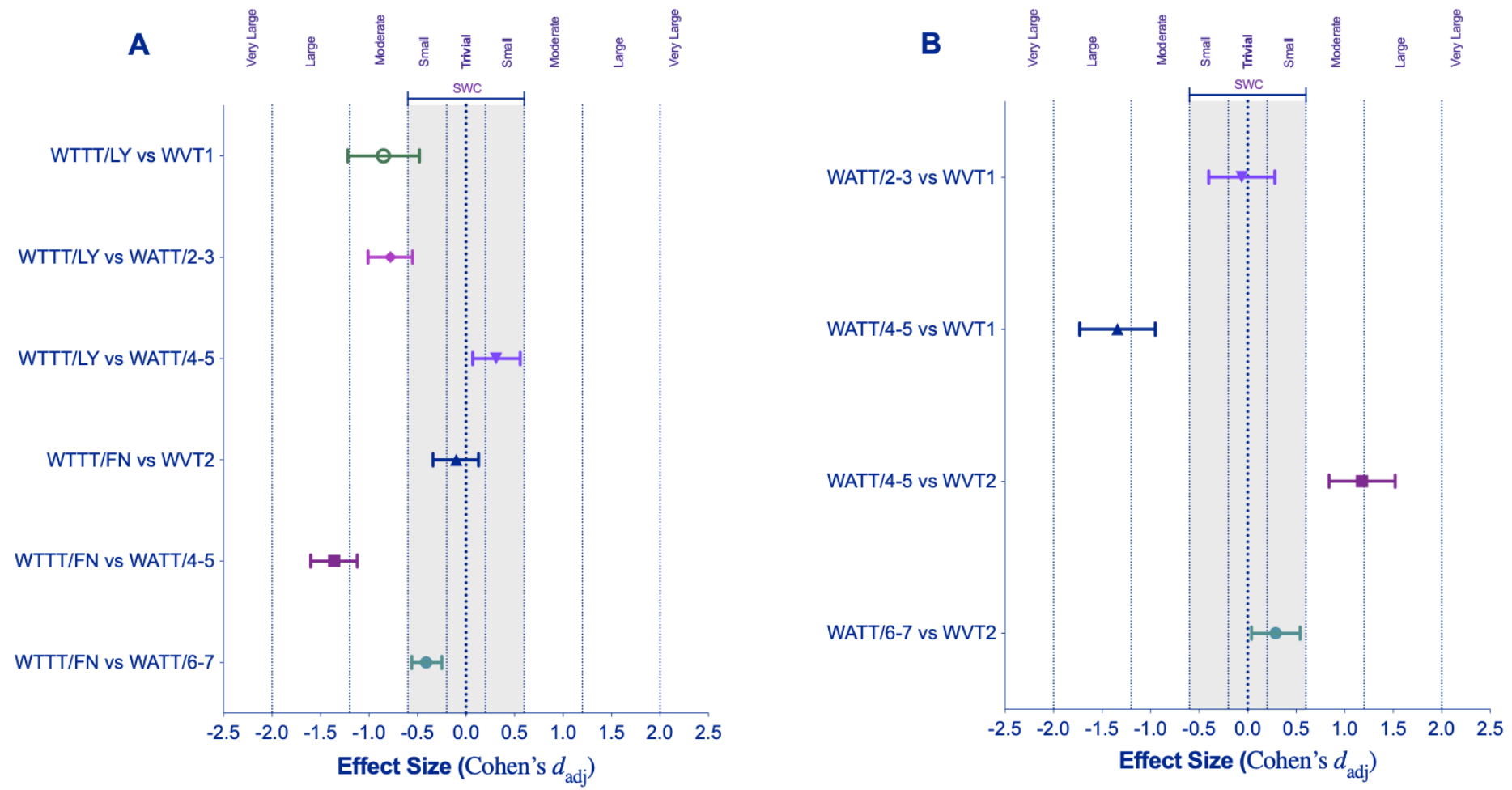

Figure 2 
Mean difference and uncertainty for the difference ( $90 \%$ confidence interval) between A) traditional talk test and ventilatory threshold and B) alternative talk test and ventilatory thresholds. The unshaded area represents our statistical equivalence region. Abbreviations: SWC: Smallest worthwhile change; WTTT/LY: Watts of traditional talk test in the last stage where the answer was "yes"; WVT1: Watts at ventilatory threshold 1; WATT: Watts of alternative talk test; WTTT/FN: Watts of traditional talk test in the first stage where the answer was "no"; WVT2: Watts at ventilatory threshold 2; W: Watts.
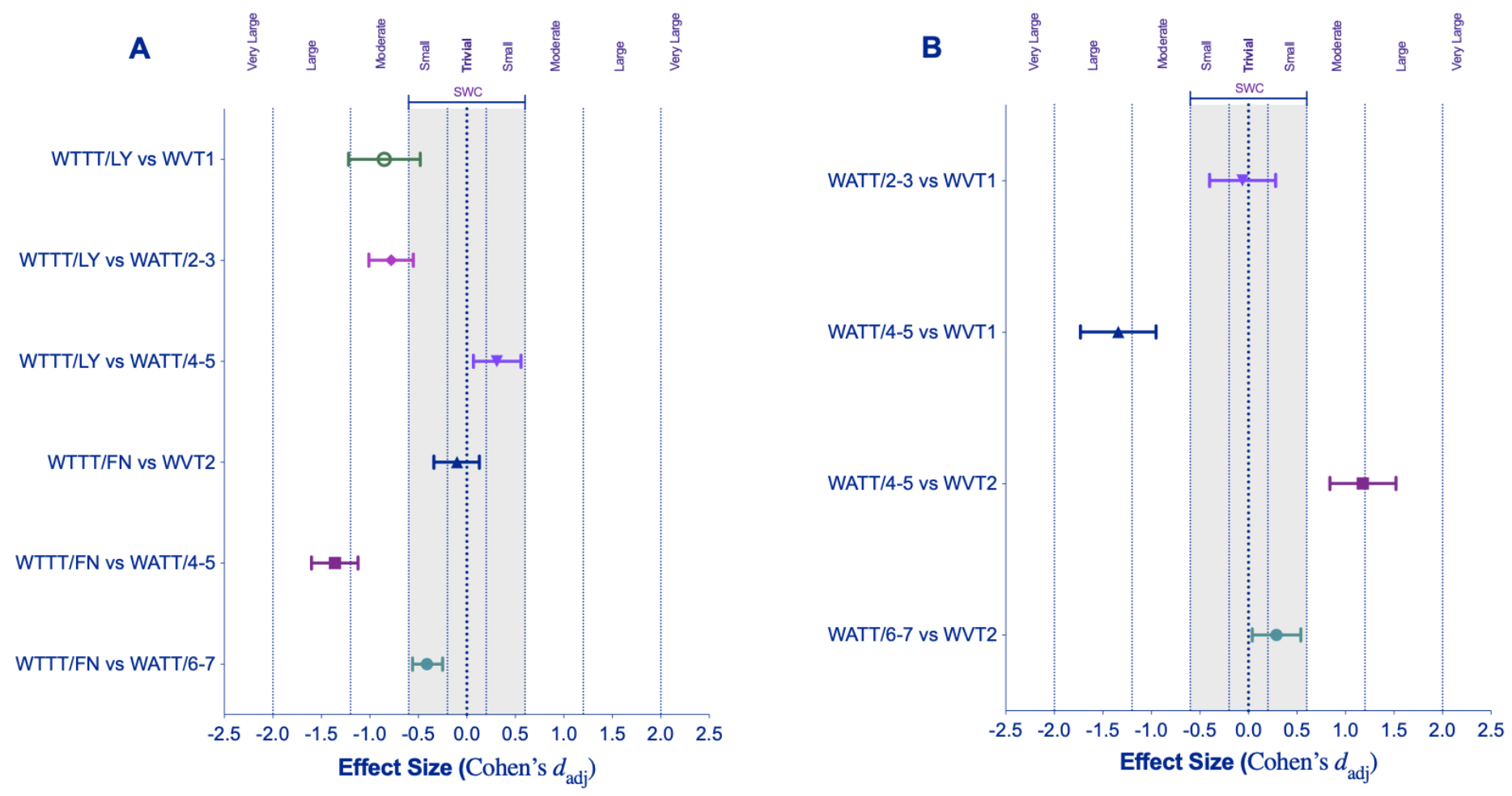

\section{Figure 2}

Mean difference and uncertainty for the difference ( $90 \%$ confidence interval) between A) traditional talk test and ventilatory threshold and B) alternative talk test and ventilatory thresholds. The unshaded area represents our statistical equivalence region. Abbreviations: SWC: Smallest worthwhile change; WTTT/LY: Watts of traditional talk test in the last stage where the answer was "yes"; WVT1: Watts at ventilatory threshold 1; WATT: Watts of alternative talk test; WTTT/FN: Watts of traditional talk test in the first stage where the answer was "no"; WVT2: Watts at ventilatory threshold 2; W: Watts. 